\title{
A imagem e sua construção a partir da hierarquia de leitura das suas estruturas compositivas \\ Universidade Paulista
}

//I/I/I/I/I/I/I/II Wilmar Gomes de Souza 


\section{Resumo}

Sobre o processo de leitura da imagem direta, perceptível, que mesmo na ausência de estímulos visuais pode ser evocada através da observação, memorização e interpretação. Procura-se apresentar um desdobramento desse conceito que elege a construção de outra hierarquia na leitura visual, onde o percurso de memorização se adere ao de observação e cede lugar à qualificação da imagem. Apresenta ainda, uma reflexão sobre a imagem como construto comunicacional e mediador, analisa suas estruturas construtivas e os elementos formais que a compõem.

\section{Palavras-chave}

Imagem, poética, estética, significação.

\section{Abstract}

Reading the image directly perceptible, even in the absence of visual characters, can be evoked through observation, memorization and interpretation. Providing a displacement of this concept that elects the construction of another hierarchy in the visual reading, memorizing the route where it joins the observation and gives rise to the classification of the image. Also presents a reflection on the image element as mediator and communication, analyze their structures and constructive formal elements that compose it.

\section{Key-words}

Image, poetic, aesthetics, signification. 


\section{Construindo um modelo de leitura da imagem a partir das suas estruturas compositivas}

A alfabetização visual e o processo de educação dos sentidos orientam-nos no entendimento dos códigos comunicacionais específicos de cada linguagem. Mas é na imagem que talvez tenhamos a maior possibilidade de compreender e contextualizar a mediação oferecida pelo universo imagético que nos rodeia. Tal compreensão possibilita que o indivíduo se comunique e lance sobre o mundo seu olhar, qualificando o universo das coisas e suas estruturas de acordo com seu código de valores. Nesse sentido, temos desvelados todos os atributos estruturais e compositivos que constroem a imagem e o seu discurso, e é justamente na apropriação dos signos, na mimese, na simulação dessas estruturas, que residem os atributos fundamentais para a compreensão do universo das imagens.

Pensar o mundo culturalmente é considerar o diálogo por meio das diversas possibilidades que a imagem proporciona, vislumbrando-a, de um lado, como um significante figural (Figura 1) e, de outro, como um significado que é também o objeto referência, atribuindo ao universo das coisas um significado maior no sentido estético, e assim, defender o princípio que diz que toda imagem constitui um dos alicerces da comunicação. Isso porque cada imagem traz uma carga emblemática carregada de idéias, sentimentos e saberes, elementos essenciais na construção da sua identidade. 

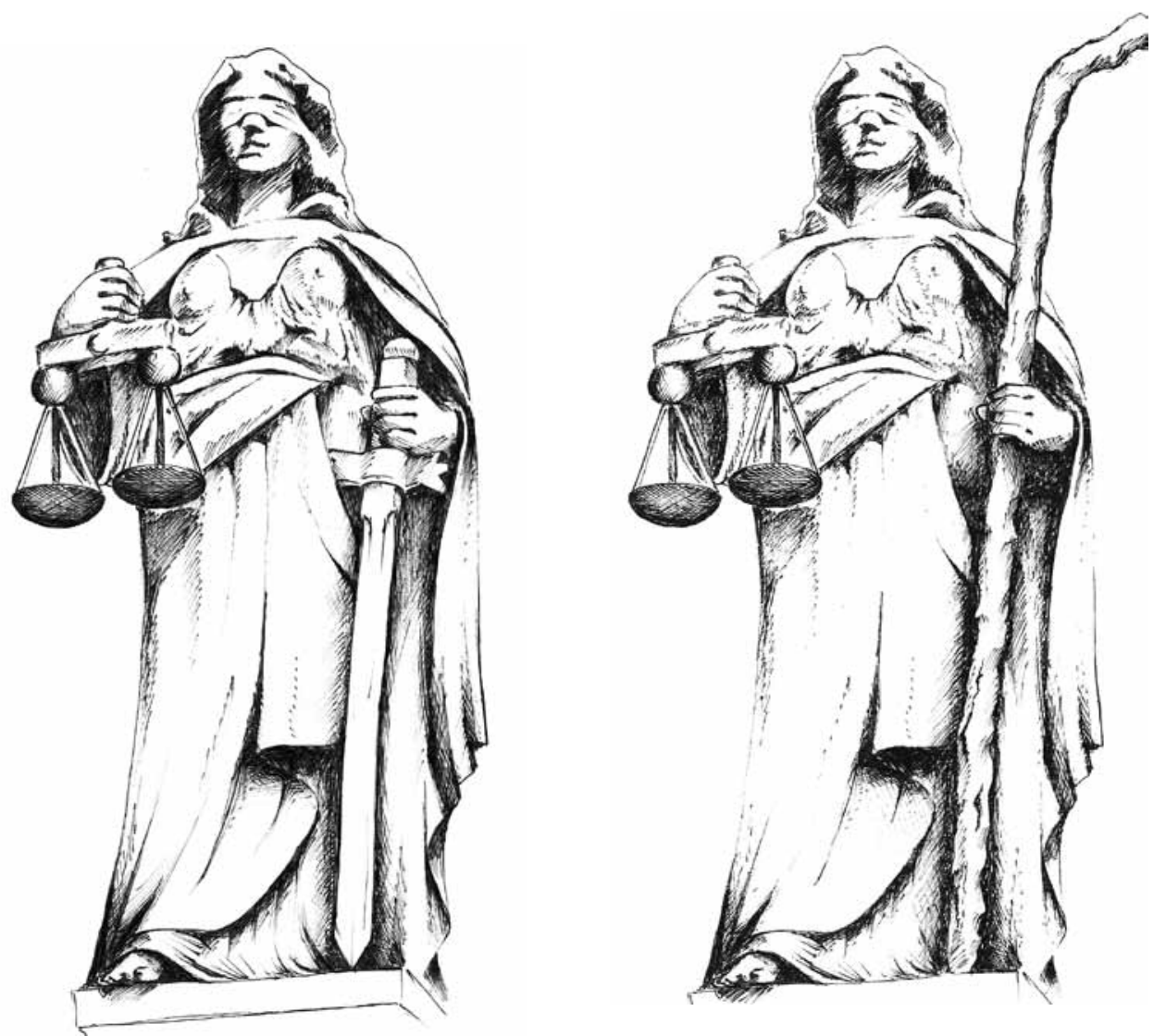

$\mathrm{O}$ ir e vir do sujeito dentro da imagem-objeto que se projeta como ferramenta de mediação das significações, é o que recria ou cria Figura 1. o sentido dado às coisas, a apropriação dos códigos expressivos específicos de cada linguagem se faz necessária na criação de um vocabulário comunicacional e na construção de uma relação que possibilite a interação com o universo imagético que nos cerca, permitindo uma relação interpessoal assim como a valorização dos elementos que compõem nosso dia a dia em todos os seus níveis de percepção da imagem.

O conceito de imagem se divide num campo semântico determinado por dois pólos opostos. Um descreve a imagem direta e perceptível, ou até mesmo existente. O outro contém a imagem mental simples, que, na ausência de estímulos visuais, pode ser evocada.

(SANTAELLA, 2008, p.36) 
Moles (1972) propõe ainda uma hierarquia de planos de percepção que compreende as seguintes categorias: (1) impulsos visuais mínimos no limiar da percepção ótica; (2) morfemas da percepção geométrica; (3) imagens parciais de objetos significantes; (4) "sintagmas" icônicos; (5) discursos icônicos; (6) seqüência de imagens

Em conformidade com sua semiótica geral, Bense (1971, p.9297) postula uma "semiótica visual como essência dos problemas de linguagem visual", nesse sentido ele defende o princípio de que toda imagem é constituída basicamente por unidades de cor e formas, aos quais ele denomina cronemas e formemas.

Os primeiros são todas as cores diferenciáveis, os últimos elementos geográficos-topológicos, como pontos, linha, áreas ou corpos. Formemas e Cronemas se unem, então, em um signo visual.

Dentro desse contexto ainda podemos destacar como grande influência, o sistema de variáveis visuais desenvolvidas por Bertin (1967, p.50) que postula na sua semiologia gráfica, segundo a qual, imagens são compostas por seis unidades elementares: cor, forma, tamanho, grau de claridade, padrão e direção (Apud, SANTAELLA, 2008).

As imagens serão observadas sempre na qualidade de signos que tem como objetivo representar aspectos do mundo visível e de si mesmas, como figuras puras ou abstratas. Configuram o mundo físico, metafísico e virtual em que habitamos, se imbricam e causam transformações comportamentais, criam vínculos e nos levam a buscar relações de afeto, similaridade e identificação com o universo que nos rodeia.

Este artigo propõe uma abordagem não ortodoxa da imagem, além da reflexão sobre os caminhos que possibilitam a sua leitura, analisando conceitos estruturais que configuram sua significação, levando em conta ainda as considerações da ciência da cognição e sua busca por unidades mínimas de percepção da imagem quer seja nos cronemas e formemas de Bense (1971), nos pictogenes de Zimmer (1983) ou nos geones de Biedermann (1987), assim como nos elementos formais e informais que constroem a estrutura da imagem.

Propõe ainda uma reflexão sobre os princípios culturais, sociais e estéticos que desvelam o tangível e deslocam significados, revelando na imagem todo o seu potencial comunicacional e propõe a construção de um modelo sintático de estudo da imagem que divide sua leitura em três estratos: observação, qualificação e memorização. 


\section{Conceituando a imagem}

Toda imagem nasceu para iludir e aludir nossa efêmera consciência do mundo. A imagem é um universo caótico em crescente expansão e seus limites são apenas físicos.

A percepção da imagem vem sendo descrita e discutida ao longo dos anos de diversas formas por um número cada vez maior de teóricos, é certo que o universo das imagens talvez seja aquele que ofereça mais encantos e mistérios no estudo das suas estruturas. Somos seres visuais, entendemos o universo a partir das imagens e da relação que construímos dela (a imagem) com nossos códigos de valores estéticos. É certo dizer que a integração dos planos da percepção sempre aconteceu de forma natural, o homem já o fazia nas paredes das cavernas quando usava a imagem para representar o universo que o cercava.

Para os gregos, eikon significava todo o tipo de representação imagética realizada sobre os mais variados suportes, das estampas que ilustravam selos às imagens representativas de Deuses e divindades. As primeiras eram tidas como naturais, ao passo que as segundas seriam imagens artificiais. Além desses fenômenos necessários para o registro das idéias e representações simbólicas, o conceito de imagem compreende também a imagem verbal e aquela ligada a idéia, a imagem mental. Outra distinção encontrada é aquela que faz a mediação comunicacional entre a imagem e o modelo, a oposição entre a imagem e o seu objeto de referência, entre o ser e aquilo a que remete.

Os elementos essenciais dessa concepção antiga de imagem são encontrados facilmente na atual "tipologia da imagem", segundo a qual Mitchell (1986, p.10) distingue os seguintes tipos de imagens:

1.imagens gráficas (imagens desenhadas ou pintadas, esculturas)

2.imagens óticas (espelhos, projeções)

3.imagens perceptíveis (dados de idéias, fenômenos)

4.imagens mentais (sonhos, lembranças, idéias, fantasias)

5.imagens verbais (metáforas, descrições)

Uma outra posição mediadora entre as teorias de representação mental da imagem e do signo verbal é defendida por Kossylin (1980; 1981), ele diferencia entre uma representação de imagens de superfície e uma profunda. A primeira refere-se à memória de curto prazo, 

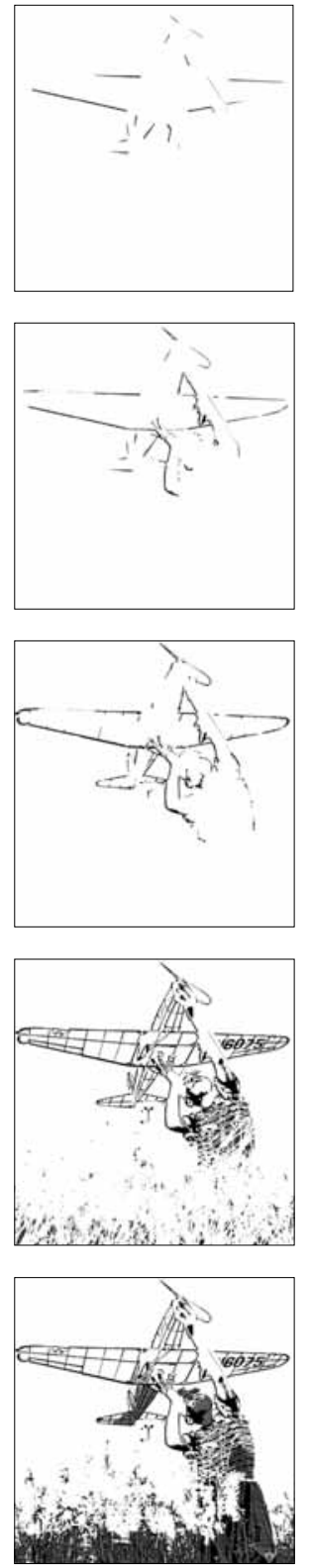

Figura 2.

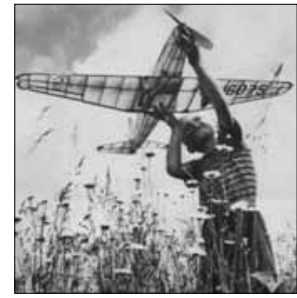

a última à memória de longo prazo. A representação imagética na memória de curto prazo é para Kossylin (1981, p.213, 217) "quase pictorial" e acontece em "meio espacial", enquanto a representação de longo prazo das imagens é literal e proposicional. Nesse caso, no entanto, a representação profunda estruturada simbolicamente pode, a qualquer momento, gerar uma representação superficial estruturada pictoricamente (Apud, SANTAELLA, 2008).

A significação da imagem vai estar diretamente ligada ao "nível fundamental do conhecimento humano" quanto mais nos apropriamos das informações e saberes que o mundo nos oferece, mais significados atribuímos aquilo que observamos.

Esse eixo, conhecimento versus significação, é que vai determinar nossa relação comunicacional com o universo imagético circundante e estabelecer vínculos de proximidade e apropriações, permitindo que possamos ver além daquilo que é apresentado e oferecido aos nossos olhos.

Uma imagem é uma superfície transparente, um compêndio estrutural onde o universo das coisas é desvelado, significado e re-significado, para que possamos entender e representar suas estruturas, atribuindo a essas significados.

O percurso de leitura da imagem é caracterizado essencialmente por um processo de apropriação das características estéticas e poéticas que configuram a imagem. Entender tal processo é parte da trajetória que percorremos para construir os alicerces que estruturam a imagem e que permite a nossa relação comunicacional com o universo das coisas.

Os caminhos que uma imagem percorre durante o processo de organização dos elementos que a constroem têm sido descritos ao longo dos anos de diversas formas por um número cada vez maior de teóricos, mas acredito que tais processos vão sempre aportar em um estágio primitivo de análise, onde o "ponto" e a linha serão a pedra fundamental de toda leitura visual (Figura 2).

Prioritariamente uma imagem se abre às singularidades interpretativas de quem a lê. Uma imagem é mediada levando em conta as similaridades ou vestígios da cultura e dos valores em que foi, ou está condicionada. Nesse sentido é correto dizer que toda imagem jamais será evocada ou entendida se em algum momento não tiver deixado suas marcas, mesmo que de forma quase imperceptível na mente do observador. O percurso de leitura das suas estruturas pode 
ser apresentado a partir da divisão em três estratos, à saber : observação, qualificação e interpretação.

Numa escala hierárquica reduziremos a estrutura do objeto ao nível mais minimalista possível e assim elegeremos o ponto como o precursor de toda a criação, condição única nesse momento da análise. A partir da sua movimentação teremos a manifestação da linha, talvez um dos elementos de maior expressão na construção da imagem, pois podemos dizer que ela traz toda uma carga emblemática de significados e significações em sua trajetória conceitual. A linha pode, portanto, ser considerada o primeiro elemento pictórico de comunicação a ser dominado pelo homem, um compêndio comunicacional que acompanha a trajetória humana do início dos tempos até os dias de hoje, um elemento mediador das linguagens. Uma linha pode, mesmo, conter grande expressividade gráfica e muita energia. Quando usada na diagonal expressa dinamismo, movimento e direção, criando tensão no espaço gráfico em que se encontra. Pode dar a sensação de estagnação ou inércia nos elementos de uma composição. Criar seções, planos e texturas, separar espaços, quando convergidas para um mesmo ponto oferecem a sensação de profundidade. Mas é acima de tudo a epígrafe que introduz a imagem em nosso universo.

Diluir o sentido geral da imagem-objeto e reconfigurála dentro de uma estrutura estética é o objetivo principal no processo de observação e o primeiro passo rumo à geração do sentido, que irá estabelecer as relações e interações entre a imagem e nosso universo de valores. A imagem recria em si mesma todo o sentido dado às coisas, devemos entendê-la como parte de um discurso que projeta e autentica suas significações. É dentro desse contexto que firmamos nossas estratégias enunciativas de leitura da imagem.

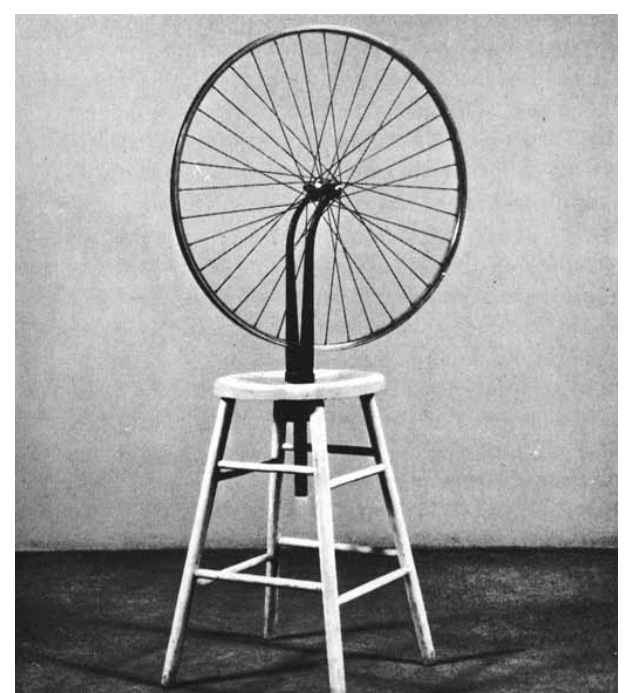

Figura 3. Roue De Bicyclete (1913)

Roda- $(64,8$ cm. de diâmetro)

Tamborete - (6o,2 cm. de altura)

Coleção particular, Milão. 


\section{Percurso de leitura da imagem}
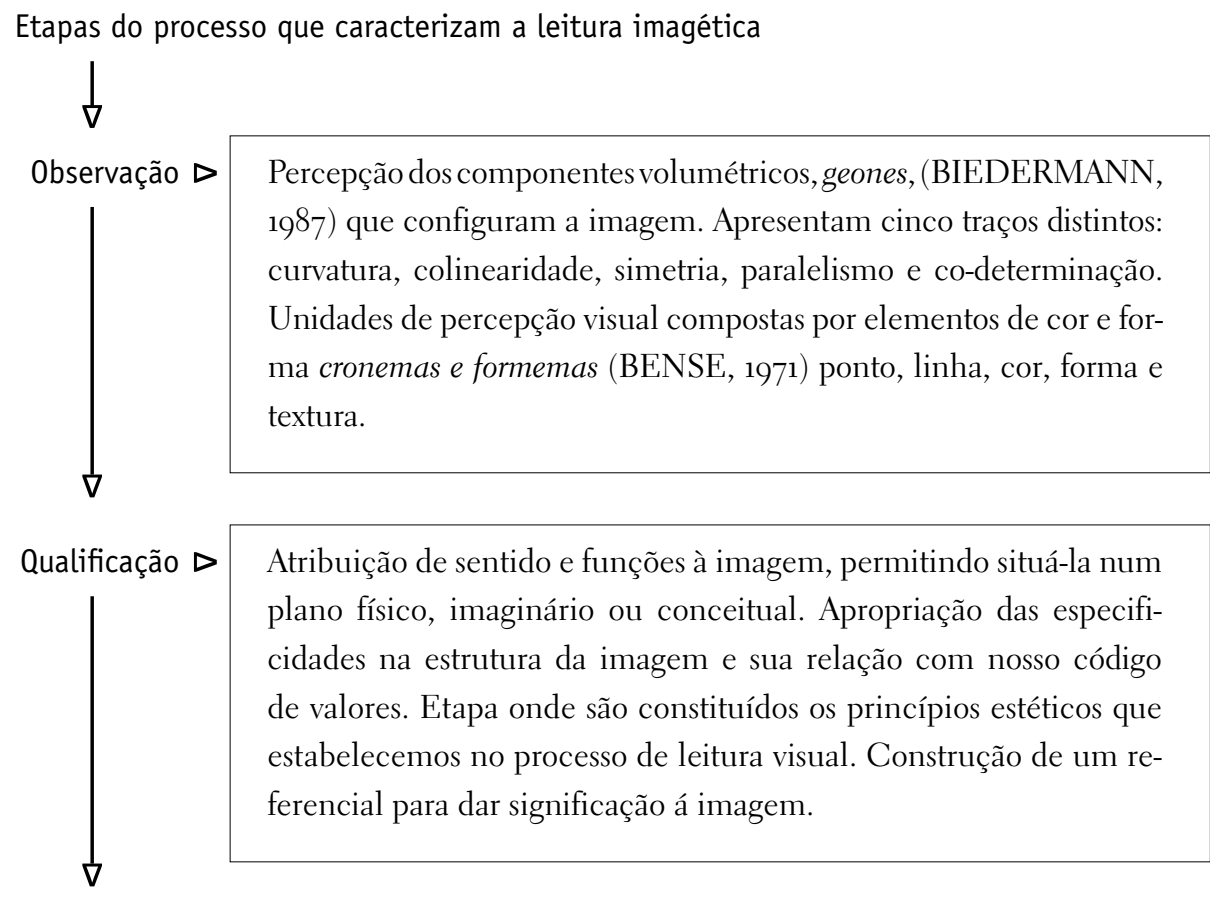

Interpretação $\triangleright$ Adaptação da imagem ao nosso universo estético. Criação de novos signos através da articulação com outras imagens (SANTAELLA, 2008). Busca de identificação que possibilite a aceitação das suas estruturas compositivas. Apropriação e integração dos códigos expressivos da imagem ao nosso universo comunicacional. Reorganização dos seus conteúdos estruturais a partir da sua fruição, reflexão e ação.

O que faz um elemento ser o que é? Quais os princípios que ordenam seu discurso no universo das coisas? Se levarmos em conta sua função em detrimento da forma talvez sejamos levados a um erro interpretativo, Marcel Duchamp (1889-1968), em 1913, já defendia uma observação não somente da função, mas da forma dos elementos que compõem nosso universo de valores onde o paradoxo das intenções normalmente é desafiado pela natureza da "não observação", não no sentido sinestésico mas sim dentro de um conceito intrínseco, que nos permite entender o significado que está além da significação (Figura 3). 
Estes ready-made , assim definidos pelo artista, transmutavam-se em obras de arte, na medida em que lhes eram atribuídos títulos, "escolhendo" este ou aquele objeto, por exemplo: uma pá de carvão retirada do mundo morto das coisas funcionais, e colocado no reino vivo das obras de arte deviam ser particularmente observadas: o olhar fazia com que se tornassem obras de arte, desafiando-nos para um entendimento das especificidades que compõem o universo das coisas.

Desejo ressaltar que a escolha destes ready-mades nunca foi ditada por consideração de prazer estético. A escolha baseava-se numa reação de diferença visual, independentemente de bom ou mal gosto... na realidade um estado de anestesia total (ausência de consciência). (RICHTER 1993, P.114)

Não interessa a disjuntiva - ou objeto ou pintura - como não interessam as separações cristalizadas entre forma e vida, olho e espírito. O objetivo da observação é entender a estrutura compositiva da imagem e os elementos que elegem sua construção, atribuindo a esses um caráter formal e intrínseco na sua concepção.

O primeiro refere-se aos aspectos exteriorizados na imagem, aos princípios constitutivos em que se inscrevem, são eles o ponto, a linha, o plano, as cores e texturas. O segundo remonta aos aspectos interiores, estão situados nas camadas mais profundas, dentro da malha expressiva das imagens.

Todo objeto da percepção é constituído por uma unidade de cor e forma. As unidades de percepção visual (perceptemas) são compostas por elementos de cor e forma: os cronemas e os formemas. Os primeiros são todas as cores diferenciáveis, os últimos elementos geográficos-topológicos, como pontos, linha, áreas ou corpos. Formemas e cronemas se unem, então, em um signo visual, assim como, na língua, sujeito e predicado se unem em uma declaração sobre "objeto" e "qualidade" (BENSE 1971, p.97)

Mas para que esse processo de observação seja tangível faz-se necessário um "desmembramento" desses elementos para análise.

Nesse sentido, a hierarquia da construção orienta e ordena o processo de composição da imagem e posteriormente de geração do sentido, primeiro a partir de uma análise constitutiva, define-se
1. Ready-made. O termo foi criado por Marcel Duchamp (1887-1968) para designar um tipo de objeto, por ele inventado, que consiste em um ou mais artigos de uso cotidiano, produzidos em massa, selecionados sem critérios estéticos e expostos como obras de arte em espaços especializados (museus e galerias). Seu primeiro ready-made, de 1912, é uma roda de bicicleta montada sobre um banquinho (Roda de Bicicleta). O ready-made de Duchamp é a atribuição resultante de experiências intelectuais e não sensoriais. O seu sentido, encontra-se, portanto, no reconhecimento destas experiências, naquilo que a elas levou, e na compreensão do caminho para onde conduzem retirando o objeto de um contexto físico, isolando-o do seu am biente usual. Duchamp afirma que os objetos não possuem um valor em si, mas que o adquirem em função do juízo de um sujeito e da validação conferida a eles pela definição de uma "autoria”. 
ponto, linha, plano, cor e textura, para então realizar uma análise dos elementos intrínsecos que a completam.

Biedermann (1987) já defendia que o reconhecimento visual dos objetos reais é armazenado no cérebro a partir de uma descrição estrutural da sua composição, suas pesquisas apontavam que tal reconhecimento depende de um repertório de 36 unidades visuais mínimas. São os chamados componentes volumétricos (sólidos geométricos simples que compõem a imagem), por ele denominados geones. Assim como os fonemas lingüísticos, é possível descrever completamente esses geones por meio de imagens através de cinco traços distintos (curvatura, colinearidade, simetria, paralelismo, co-determinação)

\section{Qualificação}

Ao observarmos o mundo a nossa volta atribuímos sentido e funções aos elementos que o compõem, mas nem sempre o fazemos de acordo com aquilo que eles representam ou buscam representar. Um processo que nos permite dar significação ao nosso universo imagético e situá-lo num plano físico, imaginário ou conceitual.

Tal processo permite ainda que nos apropriemos de especificidades desse universo e as relacionemos de acordo com nosso código de valores e conduta. É dentro desse contexto que deslocamos a imagem para nosso universo conceitual e estabelecemos vínculos estéticos, relacionando-a com outras imagens. Assim, construímos um discurso que nos permite qualificar sua forma, dentro daquilo que consideramos adequado ou belo, procuramos encontrar na imagem aspectos que autentiquem tais escolhas. Por que essa e não aquela? Buscamos similaridade, regularidade, ordem, equilíbrio e harmonia, elementos que facilitem nossa leitura imagética.

A qualificação é um processo histórico, realizado pelo homem durante toda a sua existência e como tal não pode ser analisado desvinculado dos fatores que concorrem para sua construção. É resultante de um processo de interatividade que não pode ser construído solitariamente, qualificar significa também repensar as estruturas de determinado elemento, selecionando os aspectos que tenham alguma relação de similaridade entre si ou com o observador.

A qualificação passa a ser a etapa onde são constituídos os valores estéticos que estabelecemos na leitura da imagem, e onde o 
real é desvelado, promovendo experiências que reafirmem a significação que aferimos aos elementos que compõem o universo imagético que nos rodeia, tornando inseparável a compreensão das experiências visuais do restante dos sentidos. Reordenamos e sistematizamos à todo instante os processos de leitura visual, adaptando-os á nossa conduta. É através da mimese e da análise das suas estruturas compositivas, que qualificamos a imagem buscando uma flexibilidade na compreensão das significações que sustentam tais princípios. Contribuindo, dessa maneira, para que as estruturas da linguagem visual não se distanciem de uma realidade comunicacional. Uma realidade que produza sentido, e que trabalhe a materialidade conceitual dos elementos, revigorada através do diálogo estético exposto pela qualificação dos signos que integram nosso universo imagético.

Nesse sentido, podemos afirmar que a nossa relação com a imagem tem como ponto de partida a geração do sentido que a experiência visual proporciona a partir da observação dos seus aspectos compositivos, e da aceitação, ou da não aceitação estética que determinado elemento apresenta.

A qualificação dos objetos se manifesta quando construímos (a partir do nosso código de valores) um referencial sobre os significados e significações da imagem, o que nos permite uma identificação do universo imagético que nos rodeia, vinculando aquilo que nos é familiar ou destacando a realidade que buscamos, e que nos permite entender o mundo através da leitura estética (o feio, o belo).

Essa situação possibilita a qualificação das intenções que toda imagem carrega em sua estrutura compositiva e que de certa forma nos remete a um processo de interação, investigação e organização da forma, que nos permite atribuir os valores filosóficos, culturais e modais à imagem.

A significação da imagem vai estar diretamente ligada ao "nível fundamental do conhecimento humano" quanto mais nos apropriamos das informações e saberes que o mundo nos oferece, mais significados atribuímos aquilo que observamos.

Esse eixo, conhecimento versus significação, é que vai determinar nossa relação comunicacional com o universo imagético onde estamos inseridos, e estabelecer vínculos de proximidade e apropriações, permitindo que possamos ver além daquilo que é apresentado e oferecido aos nossos olhos. 


\section{Interpretação}

Interpretar o universo imagético que nos cerca é um processo de expressão pelo qual articulamos nossas experiências e as contrapomos com nossas interações com o mundo, o que nos permite reconhecer na imagem possibilidades de interferência e adaptação dos sentidos que suas estruturas compositivas inferem em nosso código de valores.

A possibilidade de a imagem comportar, além de sua materialidade icônica ou indicial, níveis simbólicos onde significados e conceitos se abram à interpretação (ou à criação de novos signos na mente do receptor) provém sempre de um modo de articulação com outras imagens. (SANTAELLA 2008, p.75)

Procuramos, a todo instante, semelhanças, elementos que afirmem especificidades dentro de um universo de identificações e que possam possibilitar a aceitação das estruturas que constroem determinada imagem, para isso estabeleceram prioridades, criando uma hierarquia de análise estética, determinando parâmetros que definam a ordem dos elementos estruturais que constroem a imagem; primeiro a cor, depois a forma, textura, cheiro e assim sucessivamente. A soma dessa análise é que determina dentro de um juízo estético o caráter do belo, pode-se dizer que este é o nível mais alto dentro dessa organização.

“o belo, ou o juizo sobre o belo nunca é inteiramente puro.À medida que na experiência o homem sempre se entrega à contemplação estética conforme seu estado de espírito momentâneo.Dessa forma o equilíbrio perfeito necessário à apreciação pura do belo, esse equilíbrio permanece sempre apenas uma idéia, que jamais pode ser plenamente avançada pela realidade. Nesta restará sempre o domínio de um elemento sobre o outro e o mais alto que uma experiência pode atingir é uma variação entre os dois princípios, formal e material, em que ora domine a forma e ora a realidade. A beleza na idéia, portanto, é eternamente uma e indivisivel, pois pode existir um único equilíbrio; a beleza na experiência, contudo, será eternamente dupla, pois na variação o equilíbrio poderá ser transgredido por uma dupla maneira,para aquém e para além"(SCHILLER 1795, carta XVI, p.87) 
Por conseguinte, buscamos entender as relações de organização e construção dos conteúdos que configuram sua forma, nos apropriamos das imagens que são oferecidas aos nossos sentidos diariamente. Integramos nelas códigos expressivos com base em nossas experiências cotidianas, organizamos e reorganizamos conteúdos estruturais dentro da imagem, significamos e re-significamos suas realidades e condições a cada olhar, abrindo assim possibilidades para entender que o significado das coisas é construído e pensado a partir da fruição, reflexão e ação.

De acordo com essa premissa o ato de interpretar a imagem pode ser considerado o desdobramento de um processo de observação e qualificação, que transmuta seus códigos expressivos e os adapta ao nosso universo comunicacional.

A imagem pode adquirir diferentes significados, que são construídos num processo singular de apropriação e desapropriação das suas estruturas compositivas. Retiramos da imagem aqueles aspectos que caracterizam sua significação e os re-adaptamos à nossa vivência, objetividade versus subjetividade, real versus imaginário, físico versus virtual. Elegemos o eixo dessas oposições como ponto referencial para entender os processos de significação das coisas. Enfim, reorganizamos e re-significamos a imagem através da nossa experiência estética.

Vale ressaltar que nenhum conceito é absoluto, nenhuma imagem está completa, irá sempre faltar a cor, a textura, o equilíbrio e a adaptação da forma, pois é nas entrelinhas do discurso imagético onde realizamos o diálogo com o universo.

É correto, entretanto, afirmar que a interpretação da imagem deriva de uma concepção de que a análise dos componentes das estruturas a exploração dos significados que relacionam sua significação com nosso universo de valores.

Não podemos negar que, para muitos estudioso da expressão do pensamento e da comunicação humana, principalmente nos que estão comprometidos com a filosofia, que todo discurso imagético tem como finalidade delinear claramente as estruturas, significados e significações que toda imagem apresenta, apreendendo ou não a realidade. Isso significa a possibilidade de muitas leituras, já que muitas delas são determinadas pelos contextos em que as imagens se situam. Se existe uma lógica dentro do processo de leitura imagética, podemos dizer que ela não caminha pelos trilhos lineares da dedução, mas acaba sendo subjugada pela maleabilidade das hipóteses e teorias que as configuram. 


\section{Bibliografia}

BENSE, Max. 1971. Pequena Estética. SP, Perspectiva/EDUSP.

DELEUZE, Gilles e GUATTARI, Félix, Mil Platôs Capitalismo e esquizofrenia Vol. 4 Editora 34 Ltda. São Paulo. SP (edição Brasileira) 1997

FIORIN, José Luis. 2008. Em Busca do Sentido : Estudos Discursivos : São Paulo : Contexto.

GREIMAS, A-J. 1984. Semiótica Plástica e Semiótica Figurativa”, In Significação - Revista Brasileira de Semiótica,n.4 Araraquara.

MENEZES, Philadelpho. 1988. Imagem / Cinema / Poesia. Revista de Semiótica e Comunicação. PUC - São Paulo, v1, n.1, p.75.

PASCHOALE, Conrado. 1988. Alice no Pais da Geologia e o que ela encontrou lá. Revista de Semiótica e Comunicação. PUC, São Paulo, v1, n.1, p.94-96.

RICHTER, Hans Georg. Dada: arte e antiarte. São Paulo: Martins Fontes: 1993

SCHWARS, Roberto e SUZUKI, Márcio 1989. A educação Estética do homem. São Paulo: Editora Iluminuras Ltda.

SANTAELLA, Lucia e NÖRTH, Winfried. 2008. Imagem: cognição, semiótica, mídia : São Paulo : Iluminura.

AVIAN VISUAL COGNITION, Setembro de 2001. Disponível em: <http://www.pigeon.psy.tufts.edu/avc/kirkpatrick/ default.htm. Biederman, I. (1987). Recognition-bycomponents: A theory of human image understanding. Psychological Review, 94, 115-147.> Acessado em 19 de Outubro de 2010 ás 23:30

ENCICLOPÉDIA Itaú cultural, 30 de janeiro de 2008. Disponível em: <http://www.itaucultural.org.br/aplicexternas/ enciclopedia_ic/index.cfm?fuseaction=termos_texto\&cd_ verbete $=5370>$ Acessado em 19 de outubro de 2010 ás 22:16. 